\title{
Induction of Angiotensin Converting Enzyme in the Neointima after Vascular Injury Possible Role in Restenosis
}

\author{
Hiromi Rakugi, Duk-Kyung Kim, Jose E. Krieger, Dale S. Wang, Victor J. Dzau, and Richard E. Pratt \\ Falk Cardiovascular Research Center, Division of Cardiovascular Medicine, Stanford University School of Medicine, \\ Stanford, California 94305
}

\begin{abstract}
Angiotensin II (Ang II) promotes growth of vascular smooth muscle cells in vitro. Consistent with this, Ang II enhances neointimal proliferation in vivo after vascular injury, while angiotensin converting enzyme (ACE) inhibitors attenuate this process. Since tissue ACE plays a key role in the control of local Ang II production, we examined whether vascular injury resulted in an increase in vascular ACE expression that may result in increased Ang II production. Abdominal aorta of Sprague-Dawley rats were injured with a 2 French balloon catheter. Morphometrical changes, ACE enzymatic activity, and localization of ACE by immunohistochemistry in injured and uninjured aorta were analyzed. Vascular ACE activity in the injured aorta was significantly higher than in the uninjured aorta, while serum and lung ACE levels were not different between the two groups. The cellular distribution of the ACE protein in the neointima was similar to that of alpha smooth muscle actin but differed from those of endothelial (von Willebrand factor) or monocytes/macrophages (ED-1) markers, demonstrating that ACE was expressed in neointimal smooth muscle cells. These data demonstrate that vascular injury results in the induction of vascular $\mathrm{ACE}$ and suggest that the inhibition of vascular ACE may be important in the prevention of restenosis after balloon injury. (J. Clin. Invest. 1994. 339346.) Key words: growth control - restenosis - myointimal • tissue renin angiotensin system $\bullet$ converting enzyme
\end{abstract}

\section{Introduction}

Restenosis after percutaneous transluminal balloon angioplasty remains the major factor limiting favorable long-term outcome of many patients undergoing this procedure for coronary or peripheral vascular disease. The pathological process responsible for restenosis is neointimal hyperplasia, which is a fibroproliferative lesion consisting of intimal smooth musclelike cells, fibroblasts, and fibrous connective tissue $(1,2)$. Based on experimental studies, the pathobiological events in response to vascular injury have been described. These include endothelial damage, platelet activation with release of biologically active mediators, medial smooth muscle replication with

Address correspondence to Dr. Richard E. Pratt, Division of Cardiovascular Medicine, Falk Cardiovascular Research Center, 300 Pasteur Drive, Stanford, CA 94305-5246.

Received for publication 5 June 1992 and in revised form 11 August 1993.

J. Clin. Invest.

(c) The American Society for Clinical Investigation, Inc. 0021-9738/94/01/0339/08 $\$ 2.00$

Volume 93, January 1994, 339-346 subsequent migration into the subintimal region, and neointimal cellular proliferation with matrix modulation. Several cytokines and growth factors released by activated platelets or damaged vascular cells have been implicated in the initial events.

Recent data suggest that angiotensin II (Ang II) ${ }^{1}$ may play an important role in the development of the neointimal lesion in animal models. In vitro, Ang II has been shown to stimulate vascular smooth muscle growth and migration (3-8). In vivo, continuous infusion of Ang II enhanced markedly vascular smooth muscle cell (VSMC) proliferation in the injured rat arterial wall (9). Powell et al. (10) reported that angiotensin converting enzyme (ACE) inhibitors can prevent neointimal proliferation after balloon injury in rats. This effect of ACE inhibitors on experimental restenosis is due, in part, to the blockade of Ang II production, since the angiotensin receptor antagonist, DuP 753, has also been shown to be similarly effective in preventing neointimal hyperplasia $(11,12)$. However, the increase in bradykinin after ACE inhibition may also play a role $(13,14)$.

Of pathophysiologic importance is an understanding of the origin of vascular Ang II that is responsible for this VSMC response. Ang II can originate from the circulation or can be synthesized locally by endothelial ACE. Since the endothelium is denuded at the site of injury, vascular Ang II must be synthesized by nonendothelial cells in the lesion or taken up actively from the circulation. Previous reports have demonstrated that pretreatment with an ACE inhibitor (cilazapril) $6 \mathrm{~d}$ before the injury resulted in more pronounced attenuation of neointimal formation compared with treatment initiated $2 \mathrm{~d}$ before or at the time of injury (10). Furthermore, a higher dose of cilazapril was required to inhibit lesion development. It has also been shown that suppression of tissue $\mathrm{ACE}$ activity requires longer term or higher dose treatment with $\mathrm{ACE}$ inhibitor than that required for the suppression of circulating ACE activity (1517). Taken together, these results suggest that local tissue $A C E$, as opposed to serum ACE, may play a key role in the neointimal formation after balloon injury. However, the source of the tissue ACE in the endothelial denuded injured vessel is unknown. These studies were performed to examine the level of expression and the localization of $\mathrm{ACE}$ within the vessel wall during neointimal proliferation in response to balloon injury. Our experiments demonstrate that the neointima that forms in response to vascular injury contains high levels of immunoreactive ACE and ACE activity. This local increase in ACE activity may be important in enhancing Ang II production and/or bradykinin degradation in the lesion. Moreover, ACE may play an

1. Abbreviations used in this paper: $\mathrm{ACE}$, angiotensin converting enzyme; Ang II, angiotensin II; VSMC, vascular smooth muscle cell; vWF, von Willebrand factor. 
important role in the pathophysiology of neointimal hyperplasia and in determining the efficacy of ACE inhibitor in the prevention of restenosis.

\section{Methods}

Preparation of arterial injury model. Male Sprague-Dawley rats weighing 500-550 g were used. Endothelial denudation and injury to the vascular wall (18) was performed on the abdominal aorta. Rats were anesthetized with the administration of ketamine hydrochloride $(80 \mathrm{mg} / \mathrm{kg}$; Parke-Davis, Morris Plains, NJ) and xylazine ( $12 \mathrm{mg} / \mathrm{kg}$; Lloyd Laboratories, Shenandoah, IA). A 2 French arterial embolectomy balloon catheter (American Edward Laboratories, Santa Ana, CA) was passed into the aorta via the left femoral artery and placed distal to the renal arteries. The balloon was inflated sufficiently and withdrawn slowly to the aortic bifurcation. This procedure was repeated two more times. Using Evans blue staining, we documented that this procedure effectively denuded the endothelium. After removal of the catheter, the femoral artery was ligated and the wound closed. Sham-operated rats served as control. Tissues were harvested $14 \mathrm{~d}$ after injury.

Drugs administered. Quinapril, an ACE inhibitor (donated by Parke-Davis, Ann Arbor, MI), was freshly dissolved in drinking water daily and given to the rats at $10 \mathrm{mg} / \mathrm{kg}$ per $\mathrm{d}$. The consumption of drinking water was measured to confirm appropriate administration. These doses were shown in preliminary experiments to lower blood pressure by $<20 \%$ in the normotensive rats used in these studies. Previous investigations have demonstrated that this extent of the reduction of blood pressure, induced by verapamil or minoxidil, had no significant effect on neointimal formation after vascular injury $(10,19)$.

Morphometric analysis. Rats were anesthetized and blood was withdrawn from the ascending aorta via the left ventricle. The rats were then perfused at a pressure of $110 \mathrm{mmHg}$ through the ascending aorta with $100 \mathrm{ml}$ of PBS (pH 7.2), followed by $80 \mathrm{ml}$ of freshly prepared PBS containing 4\% paraformaldehyde. The abdominal aorta was removed from the branch of the left renal artery to the aortic bifurcation and cut into three portions (proximal, mid, and distal). The tissue was postfixed in the same fixative as above at $4^{\circ} \mathrm{C}$ for $4 \mathrm{~h}$ and then embedded in paraffin. The mid-portion of the abdominal aorta was used for the morphometric analysis.

To estimate the size of the intimal lesion, multiple five micron cross-sections of each vessel were stained with hematoxylin and eosin, photographed under low power, and projected onto a screen. The lesion and the vessel wall were traced carefully using a digitizing tablet (2200; Sothern Micro Systems, Atlanta, GA), and the cross-sectional areas of the neointima and the media were calculated.

Measurement of renin and ACE activities. Plasma renin activity was assayed by Ang I generation using radioimmunoassay (New England Nuclear Research Products, Boston, MA). Serum and tissue ACE activities were determined using a fluorometric assay modified from that described by Cheung and Cushman (20). This assay measures the generation of His-Leu from a hippuryl-His-Leu (Sigma Chemical Co., St. Louis, MO). Serum or homogenized vessels were incubated for 15 min at $37^{\circ} \mathrm{C}, \mathrm{pH} 7.5$, in the presence of hippuryl-His-Leu. To measure background fluorescence, samples were incubated with no added substrate. The reaction was stopped by the addition of $\mathrm{NaOH}, \mathrm{pH} 8.5$, and the His-Leu was tagged with $0.1 \%$ phthaldealdehyde (Sigma Chemical Co.) and quantitated fluorometrically at an excitation wavelength of $386 \mathrm{~nm}$ and emission wavelength of $436 \mathrm{~nm}$. The sensitivity of this assay is $\leq 0.1 \mathrm{nmol} /$ tube and the generation of His-Leu is linear from 0.1 to $13 \mathrm{nmol} /$ tube. ACE activity in the aorta was calculated as nmoles His-Leu generated per minute per milligram tissue weight (Fig. 1) or per milligram protein (Fig. 2). Protein was measured by a protein assay system (Bio-Rad Laboratories, Richmond, CA) (21). ACE activity in the plasma was calculated as the nmoles His-Leu generated per minute per milliliter of plasma.

For the quantitation of the ACE in the intimal and/or medial smooth muscle cells of the injured and noninjured abdominal aorta, rats were anesthetized and perfused through the ascending aorta with either cold PBS or cold distilled water to remove endothelial cells. As previously reported (22), water perfusion removed endothelial cells completely from uninjured aorta while PBS had little or no effect. Similarly, water perfusion but not PBS denuded the regenerated endothelial cells from the injured aorta (data not shown). In one set of experiments, the lumenal surface was scraped with a Q-tip to remove the neointima. The aortic segments were then homogenized and assayed for ACE activity. In parallel, segments were fixed with $10 \%$ formaldehyde and examined by light microscopy for the presence of neointima or immunohistochemically for the detection of von Willebrand factor ( $\mathrm{WWF}$ ) as verification for the presence or absence of vascular endothelial cells.

Immunohistochemical localization of vascular ACE. Rabbit anti-human ACE polyclonal antibody (23) was the generous gift of Drs. Mario R. W. Ehlers and James F. Riordan (Center for Biochemical and Biophysical Sciences and Medicine, Harvard Medical School, Boston, MA). Mouse anti-rat ACE mAb, IgM class (24), was purchased from Affinity Bioreagents (Neshanic Station, NJ). Rabbit anti-human factor VIII-related antigen polyclonal antibody, purchased from Dako Laboratory (Santa Barbara, CA), was used as an endothelial cells marker. Mouse anti-a smooth muscle actin mAb, purchased from Sigma Chemical Co., was used as the specific marker of the smooth muscle cells. Mouse anti-rat monocytes/macrophages mAb (ED-1) (25) was purchased from Chemicon International ( Temecula, CA).

The processing of tissue and the preparation of the sections were the same as for the morphometric analysis. $5-\mu \mathrm{m}$ sections were cut on a rotary microtome and placed on glass slides that had been treated for $20 \mathrm{~s}$ with acetone containing 2\% 3-aminopropyltriethoxysilane (Sigma Chemical Co.). The sections were digested with $0.1 \%$ Trypsin (Sigma Chemical Co.) in PBS at $37^{\circ} \mathrm{C}$ for $12 \mathrm{~min}$. Immunohistochemical detection of each antigen was accomplished as previously described (26). Briefly, the sections were preincubated with nonimmune serum from the animal species in which the secondary step antibody was produced. The sections were then covered with a specific primary antibody and incubated for $15 \mathrm{~h}$ at $4^{\circ} \mathrm{C}$, washed with PBS, and then incubated with the biotinylated secondary antibody. After washing, the sections were incubated with avidin-biotinylated horseradish peroxidase complex (Vectastain ABC kits; Vector Laboratory, Burlingame, CA), and developed with $0.02 \% \mathrm{H}_{2} \mathrm{O}_{2}$ and either $0.1 \%$ diaminobenzidine tetrahydrochloride (DAB) or 3-amino-9-ethylcarbazole (AEC). The slides were then counter-stained with hematoxy- 
Table I. Effect of ACE Inhibitor, Quinapril, on Neointimal Formation after Balloon Injury

\begin{tabular}{lccc}
\hline & $\begin{array}{c}\text { Noninjured } \\
(n=5)\end{array}$ & $\begin{array}{c}\text { Injured } \\
\text { nondrug } \\
(n=6)\end{array}$ & $\begin{array}{c}\text { Injured } \\
\text { quinapril } \\
(n=7)\end{array}$ \\
\hline Media $\left(10^{3} \mu \mathrm{m}^{2}\right)$ & $335 \pm 21$ & $343 \pm 24$ & $329 \pm 13$ \\
Neointima $\left(10^{3} \mu \mathrm{m}^{2}\right)$ & 0 & $116 \pm 9$ & $53 \pm 15^{*}$ \\
Neointima/media & 0 & $0.35 \pm 0.03$ & $0.17 \pm 0.05^{*}$ \\
\hline
\end{tabular}

Morphometric analysis of abdominal aorta 2 wk after balloon injury. Values are mean \pm SEM. Quinapril: $10 \mathrm{mg} / \mathrm{kg}$ per $\mathrm{d}$ of quinapril was given by drinking water for 1 wk before and $2 \mathrm{wk}$ after balloon injury. In the injured vessel, the neointimal area was $35 \%$ of the medial area or $25 \%$ of the vessel (medial plus neointimal) area. This decreased by $50 \%$ in the drug-treated animals. ${ }^{*} P<0.01$ vs. nondrug group.

lin. Positive staining using DAB appeared as brownish-black in color, while AEC yields a red color.

Negative controls included the following: $(a)$ omission of primary or secondary antibody; $(b)$ replacement of the primary antibody by nonimmune serum or immunoglobulins of the same species; $(c)$ for the anti-human ACE antibody, replacement of the primary antibody by the anti-human ACE antibody preabsorbed with purified human kidney ACE (gift of Drs. Mario R. W. Ehlers and James F. Riordan) (27). No staining of the tissue sections was observed in any of the negative controls.

Positive controls were as follows: $(a)$ endothelial cells of uninjured aorta served as the positive control for ACE and vWF staining; $(b)$ medial layer of aorta served as the positive control for a smooth muscle actin staining; $(c)$ peritoneal macrophages prepared from a rat served as positive control for ED-1 staining (28). All the positive controls produced the expected signals.
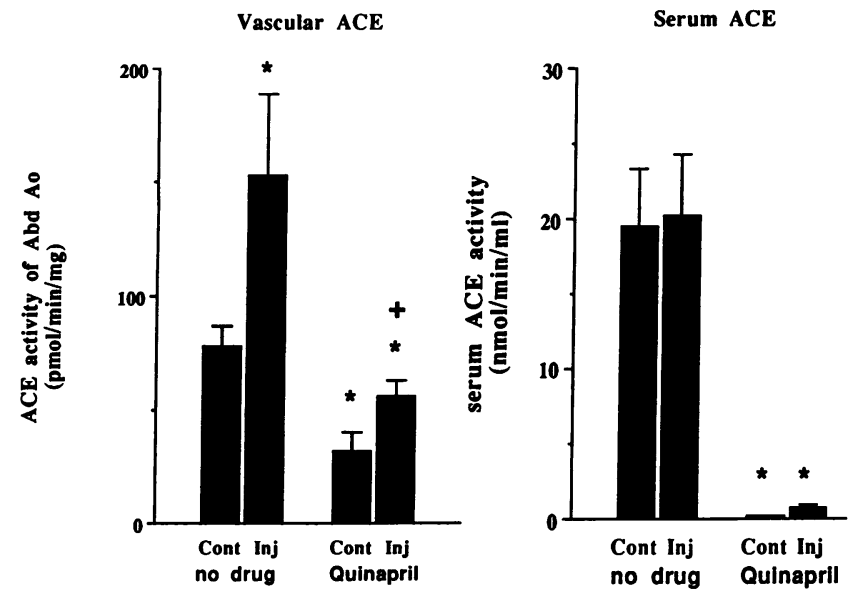

Figure 1. Effect of balloon injury and in vivo ACE inhibitors on vascular and serum ACE activities. Abdominal aortas and serum were removed from control rats (Cont) or rats who had sustained a balloon injury 2 wk previous $(I n j)$. Some of the rats had received the converting enzyme inhibitors quanapril ( $50 \mathrm{mgs} / \mathrm{kg} /$ day) starting $7 \mathrm{~d}$ before injury. ACE activity was assayed as described in Methods and is expressed as mean \pm SEM. Note that the units are picomoles product produced per minute per milligram tissue weight. $n=5-6,{ }^{*} P$ $<0.05$ with respect to control, no drug. ${ }^{+} P<0.05$ with respect to control, quinapril.
Table II. Effect of Vascular Injury on Plasma Renin Activity, Serum ACE Activity, and Lung ACE Activity

\begin{tabular}{lcr}
\hline & $\begin{array}{c}\text { Noninjured } \\
(n=5)\end{array}$ & $\begin{array}{r}\text { Injured } \\
(n=5)\end{array}$ \\
\hline PRA (ng Ang I/min per ml) & $22.3 \pm 1.9$ & $19.4 \pm 2.6$ \\
Serum ACE (nmol/min per ml) & $19.5 \pm 3.9$ & $20.2 \pm 4.1$ \\
Lung ACE (nmol/min per mg) & $3.3 \pm 0.2$ & $3.6 \pm 0.3$
\end{tabular}

Values are mean \pm SEM. PRA, plasma renin activity; ACE, angiotensin converting enzyme activity. Intergroup differences were not statistically significant.

\section{Results}

We have previously demonstrated that the rat abdominal aorta responds to balloon injury in a manner similar to the carotid artery (29). At $14 \mathrm{~d}$ postinjury, a neointimal lesion is present that is asymmetric. The area of this lesion is $\sim 35 \%$ of the medial area, while the area of the media does not change significantly from the uninjured vessel. To investigate the role of the renin angiotensin system in the lesion formation, quinapril ( 10 $\mathrm{mg} / \mathrm{kg}$ per d) was administered from $6 \mathrm{~d}$ before to $14 \mathrm{~d}$ after injury. As previously reported for the carotid injury $(10,19)$, ACE inhibition therapy resulted in a 50\% decrease in neointimal formation (Table I).

We next examined if the renin angiotensin system was activated in the balloon injured animal. As shown in Fig. 1 and Table II, the plasma renin activity, as well as the serum and lung ACE activities, were not altered after injury. In contrast, the injured aorta exhibited a twofold increase in ACE activity (Fig. 1). We studied the effect of 2-wk quinapril treatment on the inhibition of serum, lung, and vascular ACE, and observed differential responses. In response to treatment, serum ACE was completely inhibited and lung ACE was inhibited 90\%. However, vascular ACE was inhibited by only $60 \%$, even at high ACE inhibitor dose ( $50 \mathrm{mg} / \mathrm{kg}$ per d). At this dose, neointimal formation was also attenuated by $\sim 60 \%$ (data not shown).

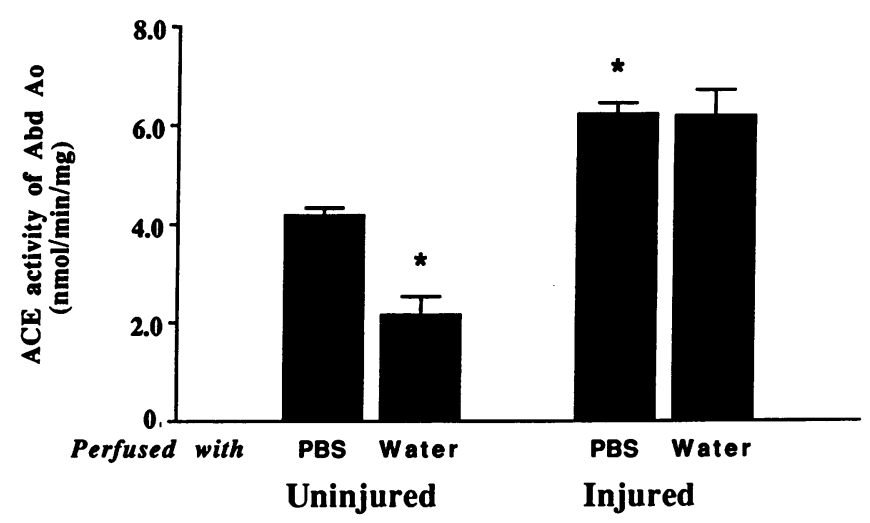

Figure 2. Effect of ex vivo endothelial removal from injured and uninjured vessels on vascular ACE activity. Abdominal aortas from control rats (Uninjured) or rats who had sustained a balloon injury 2 wk previous (Injured) were perfused ex vivo with PBS or water. ACE activity was then assayed as described in Methods and expressed as mean \pm SEM. Note that the units are nanomoles product produced per minute per milligram protein. $n=4-8,{ }^{*} P<0.05$ with respect to uninjured, PBS perfused. 

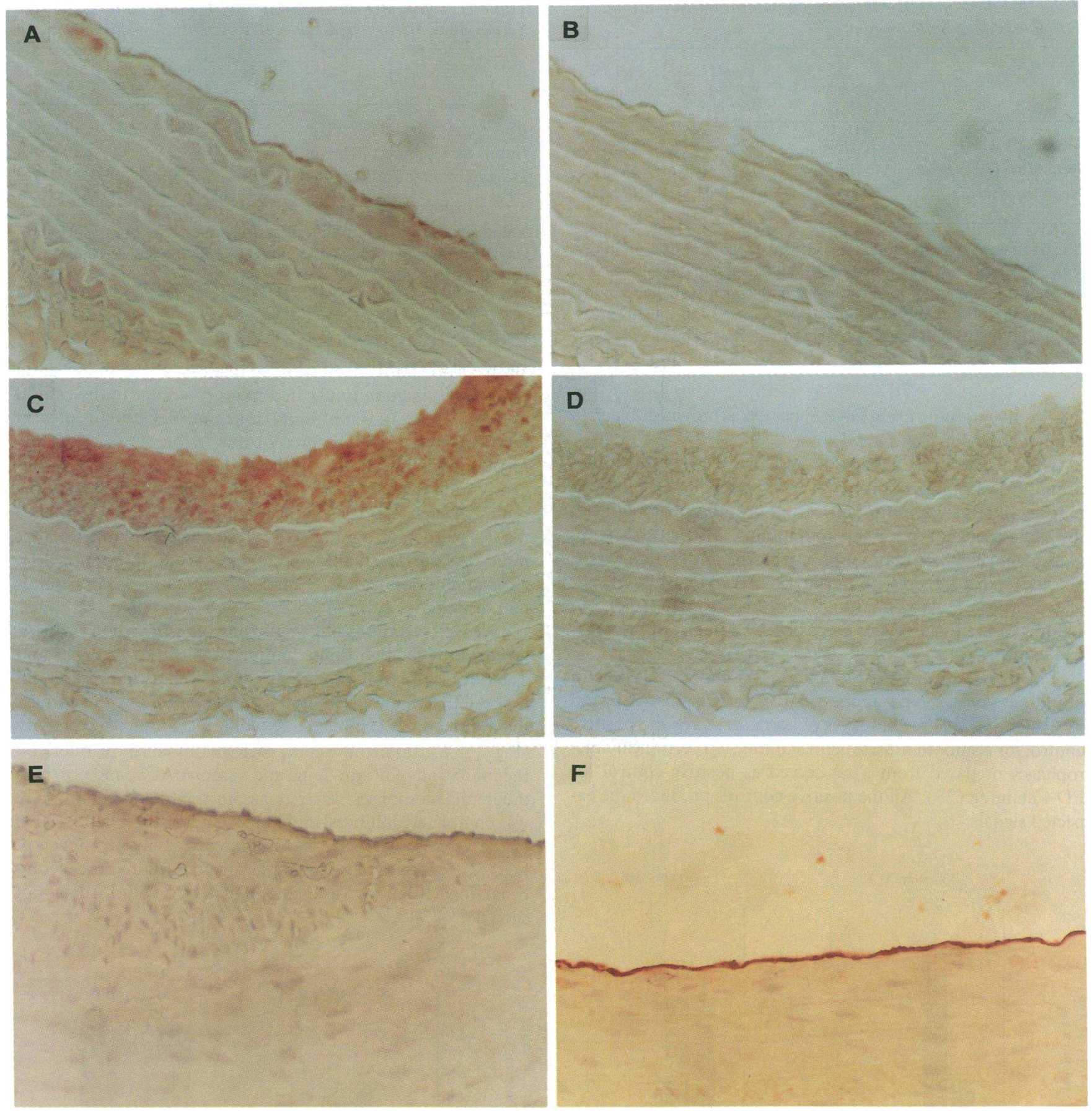

Figure 3. Localization of ACE in injured and control aortae. Aortas from control rats or rats who sustained a balloon injury 2 wk previous were analyzed for ACE using a polyclonal antibody raised against human ACE $(A-E)$ or a mAb raised against rat ACE $(F-I)$. Control uninjured vessels exhibited staining primarily of the endothelial cells $(A)$. This staining could be blocked by prior incubation of the antibody with purified human $\operatorname{ACE}(B)$. Injured vessels exhibited neointimal staining and some diffuse medial staining $(C)$. Preabsorption of the antisera with purified ACE again abolished the immunohistochemical staining $(D)$. Nonimmune rabbit serum was also negative $(E)$. A similar distribution was observed in the uninjured $(F)$ and injured $(G)$ when a mAb against rat ACE was used. This staining was specific since no signal was seen in either vessel when a control IgM was used $(H$ and $I)$.

The increase in vascular ACE in response to injury was not due to regenerated endothelial cells (Fig. 2). Water perfusion, which removes endothelial cells (as documented immunochemically), has no effect on the ACE activity in the injured aorta. Similar treatment of the uninjured aorta reduced ACE activity by $>50 \%$. Thus, the injured vessel expressed signif- cantly higher ACE activity than that seen in the uninjured vessel, and this ACE activity is contained in nonendothelial layer(s).

To identify more precisely the cells that contain $\mathrm{ACE}$, we performed immunohistochemical analysis using a rabbit polyclonal antibody raised against human ACE (Fig. 3, $A-E$ ). En- 

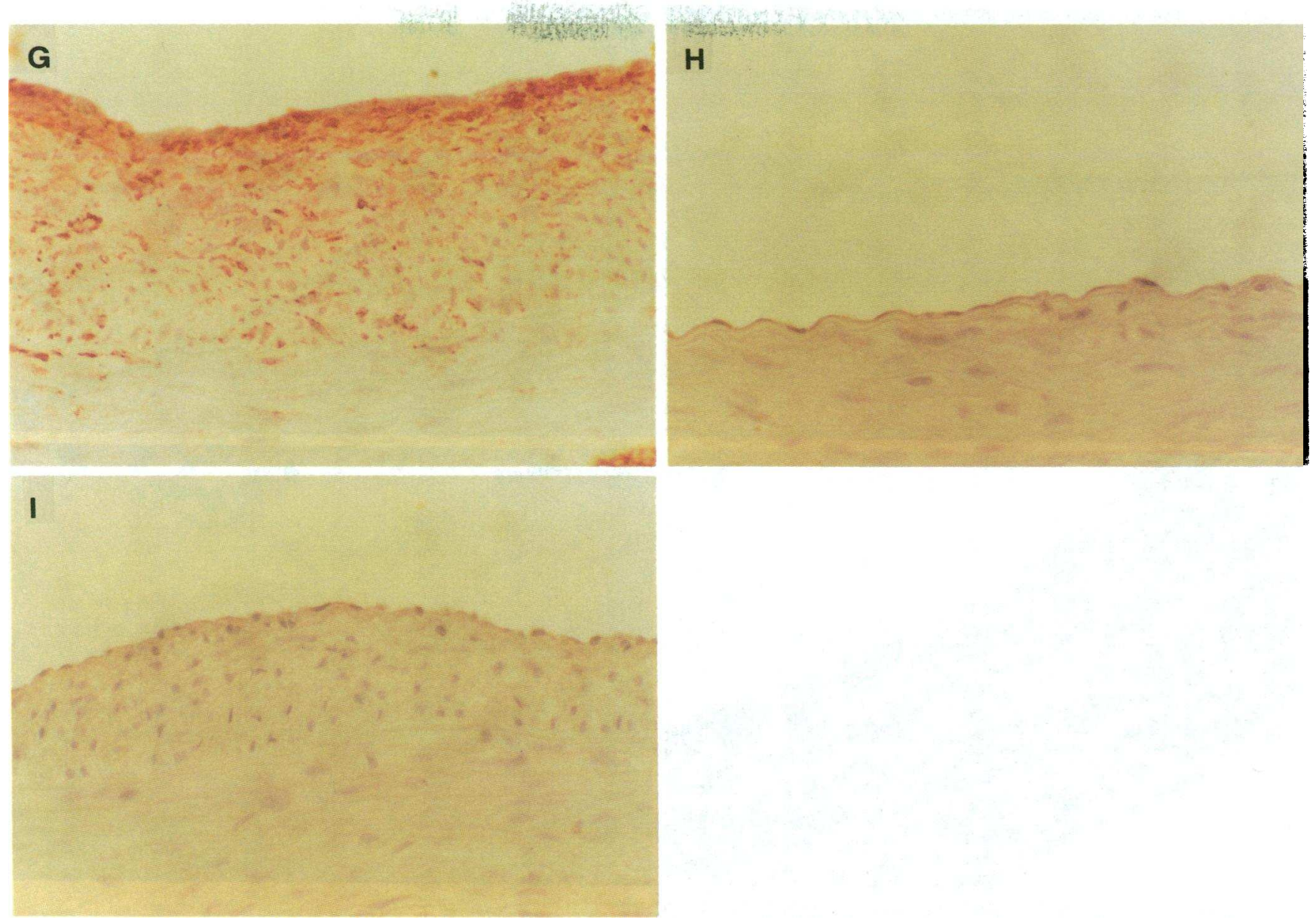

Figure 3 (Continued)

dothelial cells were identified with antibody raised against vWF (Fig. 4, $A$ and $B$ ), smooth muscle cells were identified with an antibody raised against alpha smooth muscle actin (Fig. $4 C$ ), and monocytes and macrophages were identified with an antibody raised against ED-1 (Fig. $4 \mathrm{D}$ ). In the control aorta, the endothelial cells, identified by positive staining for vWF (Fig. 4 $A$ ), stained positive for ACE (Fig. $3 A$ ), suggesting that in the control aorta, the endothelial cells were a source of ACE activity. The staining with the antihuman ACE antibody could be blocked by prior incubation with purified human ACE (Fig. 3 $B)$. Under the conditions used for the immunohistochemistry, little or no staining was observed in the medial layers. In the balloon-injured aorta, the neointimal layer stained intensely with the ACE antibody (Fig. $3 C$ ). This staining colocalized with staining for alpha smooth muscle actin (Fig. $4 C$ ) but not with staining for monocytes and macrophages (Fig. $4 \mathrm{D}$ ), suggesting its presence in the neointimal smooth muscle cells. As above, the staining in the medial layers was much less than that observed in the neointima. In some sections, patchy areas of endothelial cells staining positive for vWF could be observed on the luminal surface of the neointima (Fig. $4 B$ ), suggesting that endothelial cells contributed, to a small degree, to the ACE activity found in the balloon-injured vessel wall. No staining was observed when the ACE antibody was replaced with control rabbit serum (Fig. $3 E$ ).

Similar results were observed when an anti-rat ACE mAb was used (Fig. 3, $F-I$ ). Using this $\mathrm{mAb}$, intense staining of the endothelial layer was observed in the control vessel (Fig. $3 F$ ). In the balloon-injured vessel, intense staining was observed in the neointimal layer (Fig. $3 G$ ). In both the control and balloon-injured vessels, only weak, diffuse staining was observed in the medial layers. No detectable staining was observed in the media or in the neointima when the antibody was substituted with a control ascites fluid (Fig. 3, $H-I$ ).

These results suggest that the neointima contains ACE activity. We performed an additional experiment to address this issue directly. A group of rats underwent balloon injury of the aorta. At 2 wk postinjury, the injured aortae were removed. One group of vessels were perfused with PBS to wash off contaminating serum. A second group of vessels were perfused with cold water to remove the endothelial cells (22), and a third group of vessels were scraped with a Q-tip to remove the neointima. Aortae from rats that had not undergone balloon injury were treated similarly. The vessels were then assayed for ACE activity. As shown in Fig. 2, the ACE activity of cold water perfused vessels was not significantly different from that of PBS perfused vessels. Scraping decreased the aortic ACE activity by $40 \%(7.13 \pm 0.68 \mathrm{nmol} / \mathrm{min}$ per $\mathrm{mg}$ protein [PBS perfused] vs. $4.3 \pm 0.42 \mathrm{nmol} / \mathrm{min}$ per $\mathrm{mg}$ protein [scraped] $n$ $=7$ and 6, respectively). Morphometric analysis of the scraped vessels demonstrated that some residual neointima was present and suggested that this $40 \%$ was an underestimate. In the control vessels, removal of the endothelial cells with cold water perfusion decreased the ACE activity by $50 \%$. Scraping had no 

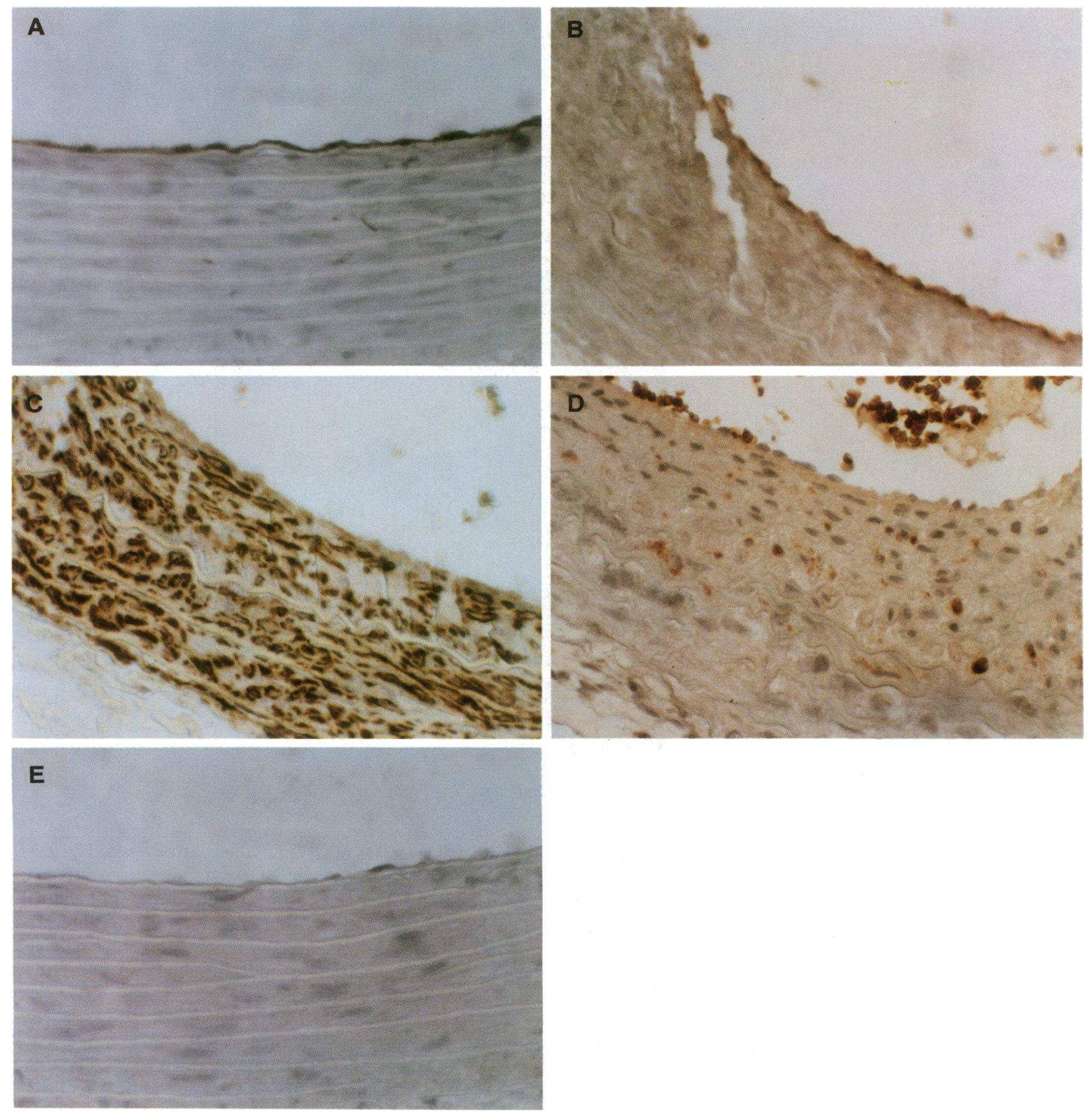

Figure 4. Cell type identification in the injured aortae. Endothelial cells in the uninjured $(A)$ and injured $(B)$ aorta were localized using a polyclonal antibody raised against vWF. The staining in both vessels was restructured to the luminal endothelial cells. Smooth muscle cells in the injured vessel were localized with an antibody against alpha smooth muscle actin $(C)$. Monocytes and/or macrophages in the injured vessel were identified with an ED-1-specific antibody $(D)$. No staining was evident when a nonimmune rabbit serum was used $(E)$. In all panels, the lumen is at the top.

additional effect $(4.4 \pm 0.27$ [PBS treated], 2.16 \pm 0.36 [water treated], and $2.25 \pm 0.47$ [scraped], $n=8,4$, and 3, respectively).

\section{Discussion}

The results of this study demonstrate that vascular injury increases ACE activity in the neointima. Our data may explain the mechanism of ACE inhibitor's action in the prevention of restenosis after balloon injury. A key to the understanding of the role of renin angiotensin in neointimal proliferation is to identify the origin of vascular ACE after injury. With the removal of the endothelium, circulating ACE could become accessible to VSMC. However, in experiments of chronic quinapril treatment, we observed a dissociation between circulating and vascular ACE activities. While serum ACE activity was completely inhibited in the quinapril-treated rats, vascular ACE activities in uninjured or injured aorta were only inhibited by $60 \%$. 
Our immunohistochemical data suggest that the cells containing ACE are primarily smooth muscle-like cells, as identified by positive costaining with a smooth muscle actin antibody. Although monocytes are known to express ACE (30, 31 ), our immunostaining data demonstrated that only a few cells in the rat neointima stained positive for the macrophage marker, ED-1, and therefore cannot account for the robust ACE immunoreactivity in many cells in the lesion. The regenerated endothelial cells could be considered as another source of ACE after injury, since we noted positive immunohistochemical staining with vWF on the luminal layer of the neointima. However, the staining was patchy and could only account for a few ACE-positive cells. Furthermore, the removal of endothelial cells by water perfusion did not change ACE activity in the injured vessels. These results suggest that the contribution of regenerated endothelial cells to the increased ACE activity in injured vessels is relatively small. Taken together, our data indicate that after vascular injury the proliferating neointimal smooth muscle cells contain high levels of immunoreactive and enzymatically active ACE.

The residual ACE activity in the uninjured vessel after endothelial removal ( via cold water perfusion) as well as the diffuse, low level of specific immunoreactivity (especially with the anti-rat $\mathrm{mAb}$ ) in the medial layer of both the injured and uninjured vessel, suggest that the medial layer contains ACE. Immunohistochemical analysis suggests that the content on a per unit area (roughly equivalent to a per cell basis) is much higher in the neointima than in the media. However, the current data do not allow a more accurate assessment of the relative per cell expression of $\mathrm{ACE}$ in the medial and neointimal regions nor does it allow an assessment of the effects of injury on the medial expression of ACE. At 2 wk after injury, the neointima represents only $25 \%$ of the total area of the injured vessel (Table I), whereas the ACE activity in the injured vessel is threefold higher than in the deendothelialized (cold water perfused) noninjured vessel (Fig. 2). While there is no apparent increase in immunoreactivity in the medial region of the injured vs. the uninjured vessel, quantitation by immunohistochemistry is not accurate. Physical scraping of the neointima decreased the ACE activity in the injured vessel by $40 \%$, but this is a minimum estimate of the contribution of neointimal ACE to total vascular ACE since these scraped vessels contained residual neointima. Therefore, the most consistent and accurate interpretation is that the increase in vascular ACE activity after injury may be due both to an increase in medial ACE expression as well as the development of a neointima that, on a per cell basis, contains much higher levels of ACE.

Similarly, the area of the endothelial layer in the uninjured vessel is several orders of magnitude lower than that of the media, yet the endothelial layer contains $\sim 50 \%$ of the ACE activity (Fig. 2). Thus, on a per unit area basis, the quantity of $\mathrm{ACE}$ in the endothelial cells is many-fold higher than in the medial layer.

Previous studies demonstrated that neointimal smooth muscle cells exhibit many of the characteristics of neonatal smooth muscle cells. The data of Schwartz and coworkers (3234 ) suggest that the neointimal and neonatal smooth muscle cells may be of the same lineage. Thus, the expression of ACE in the neointimal smooth muscle cells is consistent with the concept that these cells originate from a select population or assume a fetal phenotype in response to injury. Indeed, our preliminary data that cultured neonatal smooth muscle cells express ACE provide further support for this hypothesis (35).
Based on the in vitro and in vivo effects of Ang II on smooth muscle migration and proliferation (3-9), one might conclude that the action of ACE inhibition is the result of inhibition of Ang II production. Indeed, recent data have demonstrated that the AT-1 receptor antagonist, Dup 753, can also prevent the neointimal formation in the rat carotid artery (11, 12) or abdominal aorta (Rakugi, H., and R. E. Pratt, unpublished data). Moreover, Ang II infusions can overcome the blockade of lesion development by ACE inhibitors (11). The inhibition of ACE-mediated kinin degradation may also contribute to the growth inhibitory action of ACE inhibitors since it has been shown that HOE 140, a kinin receptor antagonist, can blunt the inhibitory effects of ramapril on neointimal formation $(13,14)$. In the intact vessel, kinins may act indirectly via the stimulation of endothelial-dependent vasodilators such as endothelial-derived relaxing factor and prostaglandins (36, 37). These endogenous vasodilators have been shown to be capable of inhibiting VSMC growth. Moreover, kinins may also have a direct effect on vascular smooth muscle cells in the control or injured vessel. The relative contribution of the decrease in Ang II and the increase in kinins to the antigrowth effect of ACE inhibitors is unclear but presumably both processes are important.

The high concentration of ACE in the developing lesion may play an important role in the pathogenesis of neointimal hyperplasia leading to restenosis after vascular injury. This and other studies $(10,19)$ have demonstrated that ACE inhibitors (quinapril, cilazapril, ramapril, and captopril) can attenuate the neointimal formation after balloon injury in the rat. ACE inhibitors can also inhibit neointima formation in response to injury in the guinea pig (38), and attenuate allograft-induced intimal formation in the rat (39). In the rat carotid injury model, we have shown that the level of vascular ACE activity correlated with the severity of the lesion, suggesting a causal relationship (Rakugi, H., D. Wang, V. J. Dzau, and R. E. Pratt, manuscript submitted for publication). Recent evidence also suggests that ACE inhibitors can inhibit the development of atherosclerosis in Watanabe rabbits (40) or cholesterol fed primates (41), and can inhibit the migration of monocytes into the vessel wall (42). On the other hand, species-specific differences in the response to ACE inhibitors appear to exist since cilazapril does not inhibit neointimal development in the balloon-injured baboon (43). The relevance of these animal studies to human restenosis is being addressed by a number of clinical studies. The early results from the MERCATOR and MARCATOR clinical trials suggest that the ACE inhibitor, cilazapril, does not inhibit angiographic restenosis $(44,45)$. However, the protocol design of these two trials is significantly different from that of the animal studies. For example, data from studies using the balloon-injured rat carotid artery demonstrated that the inhibition of tissue $\mathrm{ACE}$ activities requires the higher dose or longer term pretreatment with ACE inhibitors (13-15). In the MERCATOR and MARCATOR trials, the patients were administered a "low" dose of the ACE inhibitor $(1 / 10$ and $1 / 5$ of the effective dose in animal dose, respectively) immediately after percutaneous transluminal coronary angioplasty (PTCA) (in contrast to $7 \mathrm{~d}$ before experimental vascular injury). While species specific differences in the response of an injured vessel to ACE inhibitor treatment may be an explanation, further clinical studies using an effective drug concentration for an appropriate duration before PTCA are needed to test the hypothesis in humans. Taken together, our finding that $\mathrm{ACE}$ is expressed in the neointimal lesion suggests 
further that the effective inhibition of tissue ACE may be a critical determinant of the prevention of restenosis after balloon angioplasty.

\section{Acknowledgments}

This work was supported by National Institutes of Health grants HL35610, HL-35252, and HL-42663, and the University of California Tobacco Related Disease Program grant 1RT215, an unrestricted gift from Bristol-Myers Squibb for Cardiovascular Research, and grants from Parke Davis and Syntex Research.

\section{References}

1. Waller, B. F., H. J. Gorfinkel, F. J. Rogers, K. M. Kent, and W. C. Roberts. 1984. Early and late morphologic changes in major epicardial coronary arteries after percutaneous transluminal coronary angioplasty. Am. J. Cardiol. 53:42C47C.

2. Liu, M. W., G. S. Roubin, and S. B. King III. 1989. Restenosis after coronary angioplasty. Potential biologic determinants and role of intimal hyperplasia. Circulation. 79:1374-1387.

3. Geisterfer, A. A. T., M. J. Peach, and G. K. Owens. 1988. Angiotensin II induces hypertrophy, not hyperplasia, of cultured rat aortic smooth muscle cells. Circ. Res. 62:749-756.

4. Naftilan, A. J., R. E. Pratt, and V. J. Dzau. 1989. Induction of platelet-derived growth factor $\mathrm{A}$ chain and c-myc gene expressions by angiotensin II in cultured rat vascular smooth muscle cells. J. Clin. Invest. 83:1419-1424.

5. Gibbons, G. H., R. E. Pratt, and V. J. Dzau. 1989. Angiotensin II is a bifunctional vascular smooth muscle cell growth factor. Hypertension (Dallas). 14:358. (Abstr.)

6. Naftilan, A. J., R. E. Pratt, C. S. Eldridge, H. L. Lin, and V. J. Dzau. 1989. Angiotensin II induces c-fos expression in smooth muscle via transcriptional control. Hypertension (Dallas). 13:706-711.

7. Itoh, H., R. E. Pratt, G. Gibbons, and V. J. Dzau. 1993. Multiple autocrine growth factors modulate vascular smooth muscle cell growth response to angiotensin II. J. Clin. Invest. 91:2268-2274.

8. Gibbons, G. H., R. E. Pratt, and V. J. Dzau. 1992. Vascular myocyte hypertrophy vs. hyperplasia: autocrine transforming growth factor beta determines response to angiotensin II. J. Clin. Invest. 90:456-461.

9. Daemen, M. J. A. P., D. M. Lombardi, F. T. Bosman, and S. M. Schwartz. 1991. Angiotensin II induces smooth muscle cell proliferation in the normal and injured rat arterial wall. Circ. Res. 68:450-456.

10. Powell, J. S., J. P. Glozel, R. K. Muller, H. Kuhn, F. Hefti, M. Hosang and H. R. Baumgartner. 1989. Inhibitors of angiotensin-converting enzyme prevent myointimal proliferation after vascular injury. Science (Wash. DC). 245:186-188.

11. Osterrieder, W., R. K. M. Muller, J. S. Powell, J. P. Clozel, F. Hefti, and H. R. Baumgartner. 1991. Role of angiotensin II in injury-induced neointima formation in rats. Hypertension (Dallas). (Suppl. II):60-64.

12. Kauffman, R. F., J. S. Bean, K. M. Zimmerman, R. F. Brown, and M. I Steinberg. 1991. Inhibition by DuP 753, a non-peptide angiotensin II antagonist, of neointima formation following balloon injury of rat carotid arteries. Circula tion. 84:II-141. (Abstr.)

13. Farhy, R. D., K. L. Ho, O. A. Carretero, and A. G. Scicli. 1992. Kinin contribute to the antiproliferative effect of ramipril. J. Hypertens. 10 (Suppl. 4):S42 (Abstr.)

14. deBlois, D., D. M. Lombardi, M. A. Garvin, and S. M. Schwartz. 1992. Inhibition by ramapril of intimal hyperplasia in the denuded rat carotid is reversed by HOE 140, a kinin B2 receptor antagonist. Circulation. 86:I-226 (Abstr.).

15. Johnston, C. I., B. Fabris, H. Yamada, F. A. O. Mendelsohn, R. Cubela, D. Sivell, and B. Jackson. 1989. Comparative studies of tissue inhibition by angiotensin converting enzyme inhibitors. J. Hypertens. 7 (Suppl. 5):511-516.

16. Kaplan, H. R., D. G. Taylor, S. C. Olson, and L. K. Andrews. 1989. Quinapril: a preclinical review of the pharmacology, pharmacokinetics, and toxicology. Angiology. 40 (4, part 2):335-350.

17. Nakata, K., K. Nishimura, T. Takada, T. Ikuse, H. Yamauchi, and T. Iso. 1987. Effects of an angiotensin converting enzyme (ACE) inhibitor, SA446, on tissue ACE activity in normotensive, spontaneously hypertensive, and renal hypertensive rats. J. Cardiovasc. Pharmacol. 9:305-310.

18. Clowes, A. W., M. A. Reidy, and M. M. Clowes. 1983. Mechanisms of stenosis after arterial injury. Lab. Invest. 49:208-215.

19. Powell, J. S., R. K. M. Muller, and H. R. Baumgartner. 1991. Suppression of the vascular response to injury: The role of angiotensin-converting enzyme inhibitors. J. Am. Coll. Cardiol. 17:137B-142B.

20. Cheung, H. S., and D. W. Cushman. 1973. Inhibition of homogeneous angiotensin-converting enzyme of rabbit lung by synthetic venom peptides of Bothrop's jararaca. Biochem. Biophys. Acta. 293:451-463.

21. M. M. Bradford. 1976. A rapid and sensitive method for the quantitation of microgram quantities of protein utilizing the principle of protein-dye binding. Anal. Biochem. 72:248-254.

22. Tanimura, A., S. Tanaka, and M. Kitazano. 1986. Superficial intimal injury of the rabbit carotid artery induced by distilled water. Virchows Arch B Cell Pathol. 51:197-205.

23. Ehlers, M. R., D. L. Maeder, and R. E. Kirsch. 1986. Rapid affinity chromotography purification of human lung and kidney angiotensin converting enzyme with a novel N-carboxyalkl dipeptide inhibitor $\mathrm{N}$-[1(S)-carboxy-5aminopentyl] glycylglycine. Biochim. Biophys. Acta. 883:361-72.

24. Auerbach, R., L. Alby, J. Greives, J. Joseph, C. Lindgren, L. W. Morrissey, Y. A. Sidky, M. Tu, and S. L. Watt. 1982. Monoclonal antibody against angiotensin-converting enzyme: its use as a marker for murine, bovine, and human endothelial cells. Proc. Natl. Acad. Sci. USA. 79:7891-7895.

25. Dijkstra, C. D., E. A. Dopp, P. Joling, and G. Kraal. 1985. The heterogeneity of mononuclear phagocytes in lymphoid organs: Distinct macrophages subpopulations in the rat recognized by monoclonal antibodies ED1, ED2, and ED3. Immunology. 54:589-599.

26. Gomez, R. A., K. R. Lynch, B. C. Sturgill, J. P. Elwood, R. L. Chevalier, R. M. Carey, and M. J. Peach. 1989. Distribution of renin mRNA and its protein in the developing kidney. Am. J. Physiol. 257:F850-F858.

27. Ehlers, M. R. W., D. I. Maeder, and R. E. Kirsch. 1986. Rapid affinity chromatographic purification of human lung and kidney angiotensin-converting enzyme with the novel N-carboxyalkyl dipeptide inhibitor $\mathrm{N}$-[1(S)-carboxy-5aminopentyl] glycylglycine. Biochem. Biophys. Acta. 883:361-372.

28. Davies, R., and G. Erdogdu. 1989. Secretion of fibronectin by mineral dust-derived alveolar macrophages and activated peritoneal macrophages. Exp. Lung Res. 15:285-297.

29. Rakugi, H., H. J. Jacob, J. E. Krieger, J. R. Ingelfinger, and R. E. Pratt. 1993. Vascular injury induces angiotensinogen gene expression in the media and neointima. Circulation. 87:283-290.

30. Friedland, J., C. Setton, and E. Silverstein. 1978. Induction of angiotensin converting enzyme in human monocytes in culture. Biochem. Biophys. Res. Commun. 83:843-849.

31. Vuk-Pavlovic, Z., T. J. Kreofsky, and M. S. Rohrbach. 1989. Characteristics of monocyte angiotensin converting enzyme induction by dexamethasone. $J$. Leukocyte Biol. 45:503-509.

32. Giachelli, C., M. W. Majesky, and S. M. Schwartz. 1991. Developmentally regulated cytochrome P-4501 Al expression in cultured rat vascular smooth muscle cells. J. Biol. Chem. 266:3981-3986.

33. Majesky, M. W., E. P. Benditt, and S. M. Schwartz. 1988. Expression and developmental control of platelet-derived growth factor A-chain and B-chain/Sis genes in rat aortic smooth muscle cells. Proc. Natl. Acad. Sci. USA. 85:15241528.

34. Schwartz, S. M., L. Foy, D. Bowen-Pope, and R. Ross. 1990. Derivation and properties of platelet-derived growth factor-independent rat smooth muscle cells. Am. J. Pathol. 136:1417-1428.

35. Rakugi, H., D. Wang, C. Giachelli, S. M. Schwartz, V. J. Dzau, and R. E. Pratt. 1992. Developmentally regulated production of angiotensin converting enzyme in cultured rat vascular smooth muscle cells. J. Hypertens. 10 (Suppl. 4):S127. (Abstr.)

36. Brenner, B. M., J. L. Troy, and B. J. Bellerman. 1989. Endothelium-dependent vascular responses: mediators and mechanisms. J. Clin. Invest 84:1373-1378.

37. De Nucci, G., R. J. Gryglewski, T. D. Warner, and J. R. Vane. 1988 Receptor-mediated release of endothelium-derived relaxing factor and prostacyclin from bovine aortic endothelial cells is coupled. Proc. Natl. Acad. Sci. USA 85:2334-2338.

38. Clozel, J-P., P. Hess, C. Michael, K. Schietinger, and H. R. Baumgartner. 1991. Inhibition of converting enzyme and neointima formation after vascular injury in rabbits and guinea pigs. Hypertension (Dallas). 18 (Suppl. II):55-59.

39. Roux, S. P., J-P. Clozel, and H. Kuhn. 1991. Cilazapril inhibits wall thickening of vein bypass graft in the rat. Hypertension (Dallas). 18 (Suppl II):43-46.

40. Chobanian, A. V., C. C. Haudenschild, C. Nickerson, and S. Hope. 1992. Trandolpril inhibits atherosclerosis in the watanabe heritable hyperlipidemic rab bit. Hypertension (Dallas). 20:473-7.

41. Aberg, G., and P. Ferrer. 1990. Effects of captopril on atherosclerosis in cynomolgus monkeys. J. Cardiovasc. Pharmacol. 15 (Suppl. 5):556-572.

42. Clozel, M., H. Kuhn, F. Hefti, and H. R. Baumgartner. 1991. Endothelial dysfunction and subendothelial monocyte macrophages in hypertension. Effect of angiotensin converting enzyme inhibition. Hypertension (Dallas). 18:132141.

43. Hanson, S. R., J. S. Powell, T. Dodson, A. Lumsden, A. B. Kelly, J. S. Anderson, A. W. Clowes, and L. A. Harker. 1991. Effects of angiotensin converting enzyme inhibition with cilazapril on intimal hyperplasia in injured arteries and vascular grafts in the baboon. Hypertension (Dallas). 18 (Suppl. II):70-76.

44. MERCATOR Study Group. 1992. Does the new angiotensin converting enzyme inhibitor cilazapril prevent restenosis after percutaneous transluminal coronary angioplasty? Circulation. 86:100-110.

45. MARCATOR Investigators. 1992. Angiotensin converting enzyme inhibition and restenosis: the final results of the MARCATOR trial. Circulation. 86:I53. (Abstr.) 